NBER WORKING PAPER SERIES

DRUG SHORTAGES, PRICING, AND REGULATORY ACTIVITY

Christopher Stomberg

Working Paper 22912

http://www.nber.org/papers/w22912

\author{
NATIONAL BUREAU OF ECONOMIC RESEARCH \\ 1050 Massachusetts Avenue \\ Cambridge, MA 02138 \\ December 2016
}

I would like to thank David Kreling, Ernie Berndt, Rena Conti, Neeraj Sood, and other participants in the NBER-CRIW workshop (October, 2013) for their helpful comments on an earlier draft of this paper. I would also like to thank Erin Fox at the University of Utah Drug Information Service for kindly offering me data on shortages. Finally I would like to thank Eric Barrette for his research assistance on aspects of this paper. The views expressed herein are those of the author and do not necessarily reflect the views of the National Bureau of Economic Research.

NBER working papers are circulated for discussion and comment purposes. They have not been peer-reviewed or been subject to the review by the NBER Board of Directors that accompanies official NBER publications.

(C) 2016 by Christopher Stomberg. All rights reserved. Short sections of text, not to exceed two paragraphs, may be quoted without explicit permission provided that full credit, including (C) notice, is given to the source. 
Drug Shortages, Pricing, and Regulatory Activity

Christopher Stomberg

NBER Working Paper No. 22912

December 2016

JEL No. I11,L11,L5

\begin{abstract}
This study examines the patterns and causes of shortages in generic non-injectable drugs (e.g., tablets and topicals) in the United States. While shortages for injectable drugs have garnered more attention, shortages of other forms of prescription drugs have also been on the increase. In fact, they follow a strikingly similar trend with a number of important tablet drugs having recently been affected by shortage. This poses important questions about the root causes of these trends since most explanations found in the literature are specific to generic injectable drugs. Using a simple heuristic framework, three contributing factors are explored: regulatory oversight, potential market failures in pricing/reimbursement, and competition. This paper features an empirical examination of the contribution of changes in regulatory oversight to drug shortages. A pooled dynamic regression model using FDA data on inspections and citations reveals a statistically significant relationship between FDA regulatory activity (inspections and citations) and drug shortage rates. This result cuts across both injectable and non-injectable drugs, and could reveal a transition in equilibrium quality that should be transitory in nature, but it should also be interpreted with care given the other factors likely affecting shortage rates.
\end{abstract}

Christopher Stomberg

Bates White Economic Consulting

chris.stomberg@bateswhite.com 


\title{
DRUG SHORTAGES, PRICING, AND REGULATORY ACTIVITY
}

\author{
CHRISTOPHER STOMBERG, PH.D.
}

\begin{abstract}
This study examines the patterns and causes of shortages in generic non-injectable drugs (e.g., tablets and topicals) in the United States. While shortages for injectable drugs have garnered more attention, shortages of other forms of prescription drugs have also been on the increase. In fact, they follow a strikingly similar trend with a number of important tablet drugs having recently been affected by shortage. This poses important questions about the root causes of these trends since most explanations found in the literature are specific to generic injectable drugs. Using a simple heuristic framework, three contributing factors are explored: regulatory oversight, potential market failures in pricing/reimbursement, and competition. This paper features an empirical examination of the contribution of changes in regulatory oversight to drug shortages. A pooled dynamic regression model using FDA data on inspections and citations reveals a statistically significant relationship between FDA regulatory activity (inspections and citations) and drug shortage rates. This result cuts across both injectable and non-injectable drugs, and could reveal a transition in equilibrium quality that should be transitory in nature, but it should also be interpreted with care given the other factors likely affecting shortage rates.
\end{abstract}

\section{INTRODUCTION}

Researchers and policy-makers have devoted considerable attention in recent years to the increasing frequency and longevity of drug shortages in the United States. Many high-profile shortages have involved generic injectable drugs that are the front line treatments in important areas such as cancer where lack of availability

Date: $5 / 2014$.

I would like to thank David Kreling, Ernie Berndt, Rena Conti, Neeraj Sood, and other participants in the NBER-CRIW workshop (October, 2013) for their helpful comments on an earlier draft of this paper. I would also like to thank Erin Fox at the University of Utah Drug Information Service for kindly offering me data on shortages. Finally I would like to thank Eric Barrette for his research assistance on aspects of this paper. 
is literally a life-or-death issue for patients. Much of the research on the causes of these shortages has reasonably focused on contributing factors specific to these high-profile shortages, such as the micro structure of the generic injectable drug industry and Medicare reimbursement (see e.g. Conti \& Berndt [2]; Yurukoglu [15]; Woodcock \& Wosinska [14]).

As noted in Conti \& Berndt, however, shortages do occur for other types of drugs. While these shortages are less frequent and have generally received less attention in the press and academic research, they have also followed a similar trend. In fact, as illustrated in Figure 1 using data obtained from the University of Utah Drug Information Service (UUDIS), the pattern of ongoing shortages is strikingly similar for both types of drug. ${ }^{1}$ Although a clear level difference can be read off the y-axes of this graph, the correlation between the number of ongoing injectable and non-injectable shortages is 0.94 . Of concern, of course is the nearly four-fold increase in the number of ongoing shortages between 2007 and 2013.

There are also distinctive, and again very similar, patterns in the average length of ongoing drug shortages over time for both injectable and non-injectable drugs (see Figure 2). The correlation in these series is 0.89. Although the timing of the increase in average shortage length is more recent (beginning in 2008), this measure has nearly doubled in recent years.

The similarities demonstrated in Figures 1 and 2 are not simply an artifact of tracking the stock of drugs in shortage. ${ }^{2}$ In fact, as shown in Figure 3, the number of new shortages reported for both injectable and non-injectable drugs on a monthly basis also follows a strikingly similar pattern. ${ }^{3}$ Although the correlation between raw new shortage starts for injectable drugs and non-injectable drugs is lower, at around 0.48 , there is also considerable noise in these data. Smoothing the series using a quarterly moving average (as depicted in Figure 3) reveals a clear coherence in the patterns of shortage.

\footnotetext{
${ }^{1}$ The UUDIS which track reported shortages are described in greater detail in Section 3.1.

${ }^{2}$ Since the previous charts measure stock variables (number of shortages in progress), there is a likelihood that high correlations could be induced by the summing process inherent in computing stocks.

${ }^{3}$ Also note that the rate of new shortages in early years does not exhibit the steep ramp up over time exhibited in the two stock variables. This pattern is consistent with the way the stock variables are being calculated.
} 
Figure 1. Pattern of unresolved shortages

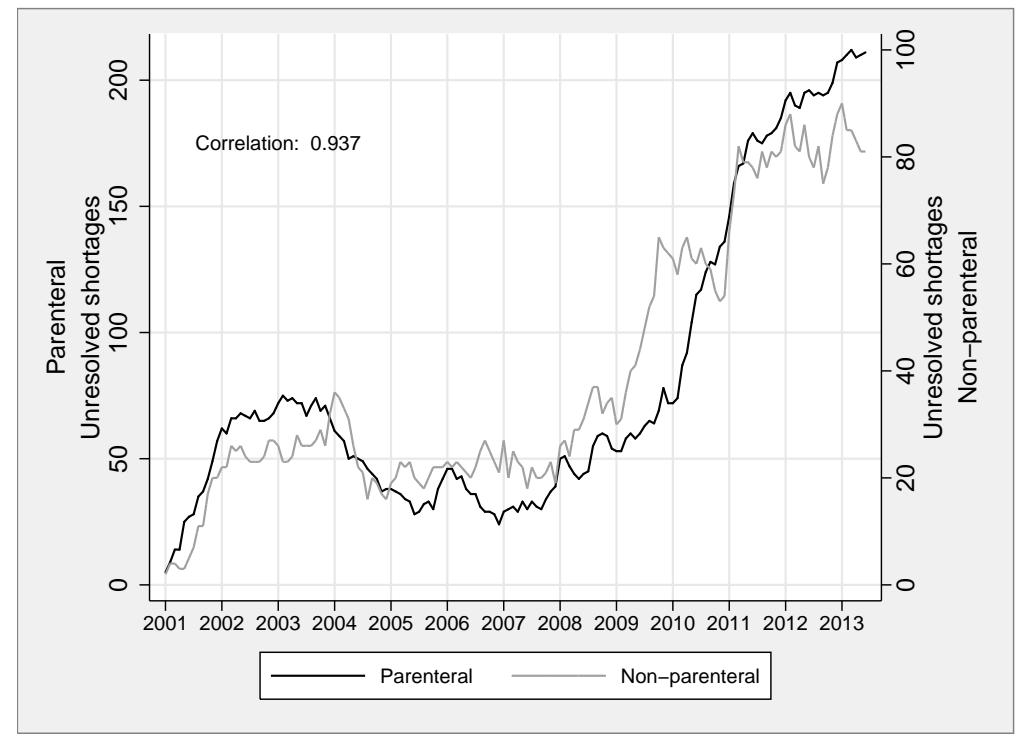

Source: University of Utah Drug Information Service (UUDIS). Vertical axis measures the number of drugs (typically molecule-form combinations) reported to be in ongoing shortage during that month. Note that early-period data are truncated on the left, and thus do not accurately reflect the actual number of shortages in progress at the time the database was initially constructed.

Although the non-injectable drugs that are the subject of these shortages may not be cancer drugs, they are nevertheless important for the treatment of many serious conditions. Table 1 below presents a selection of the non-injectable drugs that were listed by UUDIS as currently in shortage as of June 2013. A quick glance over this list reveals that several important therapies have been impacted by shortages. For example, this list includes generic forms of many former blockbuster drugs-such as Buspar, Neurontin, Cardura, and Lipitor - as well as important anti-virals and anti-infectives, such as acyclovir, doxazosin, tetracycline, and ciprofloxacin. ${ }^{4}$ The duration information, reported in months, gives an indication of the persistence of some of the supply issues. With limited supplies of these drugs available, patients

\footnotetext{
${ }^{4}$ Anecdotes can be tied to some of these drugs. For example, atorvastatin (generic Lipitor) went into shortage when the first generic entrant (and holder of market exclusivity) experienced quality problems, issued a product recall, and shut down production in response.
} 
FiguRE 2. Average age of unresolved shortages

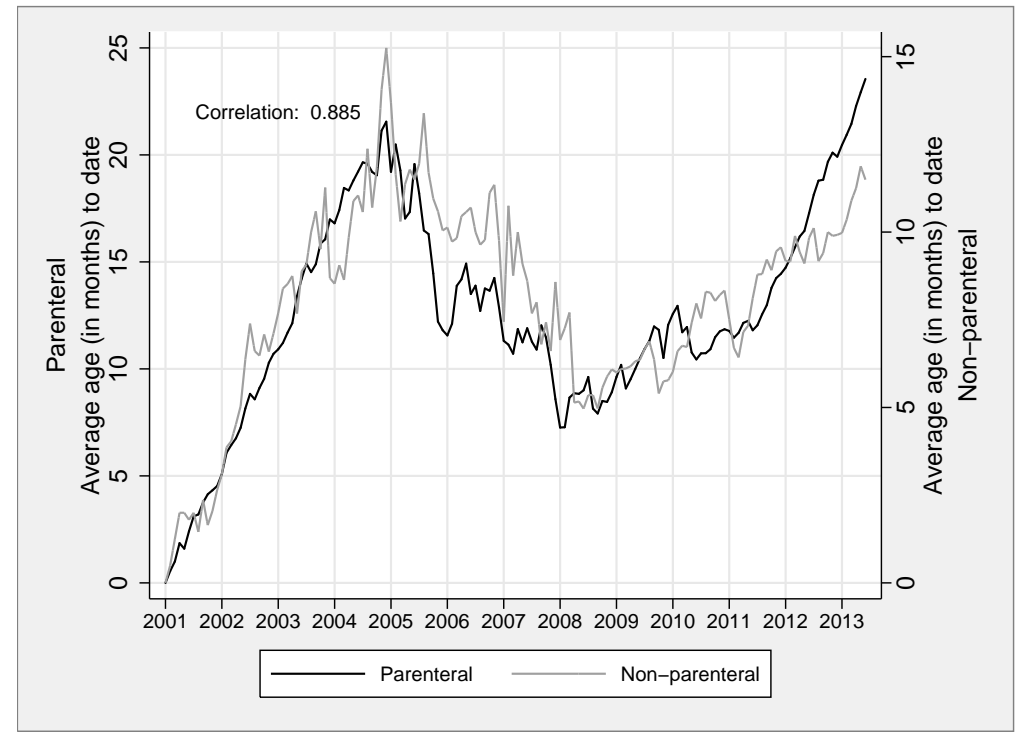

Source: University of Utah Drug Information Service (UUDIS). Vertical axis measures the average age (in months) of drugs reported to be in ongoing shortage during that month. Note that early-period data are truncated on the left, and thus do not accurately reflect the actual length of shortages in progress at the time the database was initially constructed.

have likely faced delays, interruptions, or substitutions in their therapies - with potentially adverse effects.

These trends in non-injectable drug shortages are highly relevant to an overall understanding of the causes of shortages - not just for non-injectable drugs. Whatever factors explain these trends over time, they clearly apply equally and with the same rough timing in both markets. Theories that rely on Medicare reimbursement policies — such as ASP-based Medicare Part-B reimbursement — may serve to explain level differences in shortage rates, but simply don't apply to noninjectable drugs and aren't likely to explain the consistent pattern of change over time. Similarly, theories that rely on the specifics of generic injectable production don't apply to non-injectables. Although there may exist analogues to those stories in the tablet manufacturing sector, the market-wide nature of these trends seems to lend greater weight to theories suggesting broader causes such as changes in 
FiguRE 3. Drug shortage starts

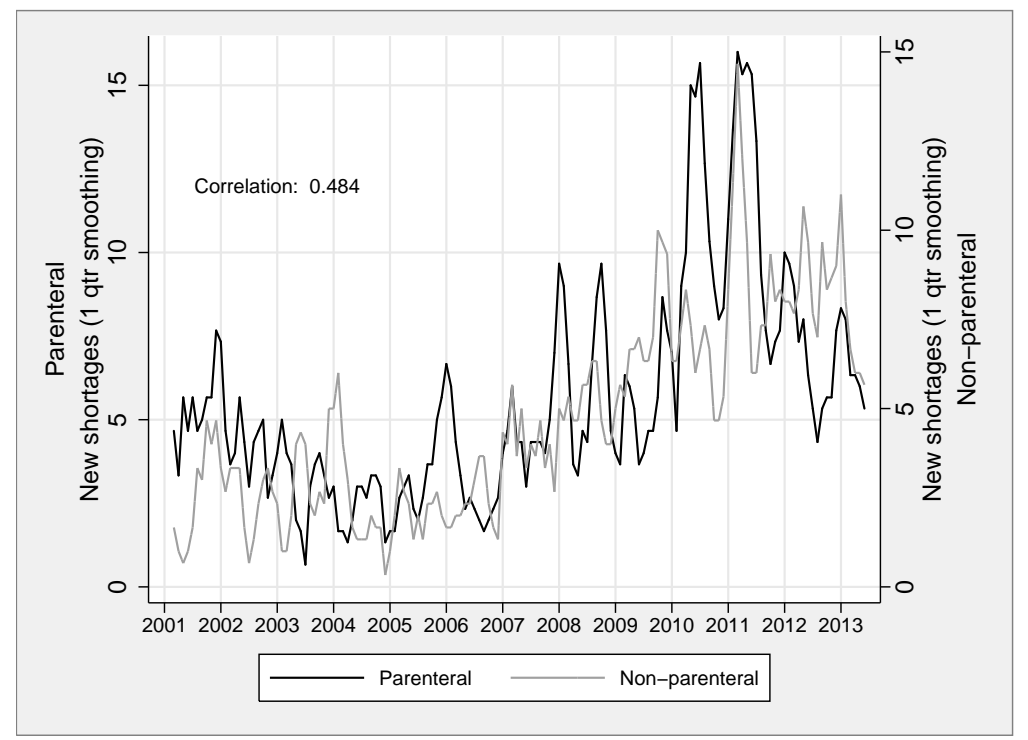

Source: University of Utah Drug Information Service (UUDIS). Vertical axis measures the monthly number of newly reported drugs in shortage smoothed using a quarterly moving average (current month plus previous two months). Reported correlation is based on non-smoothed data.

competition, market structure, and quality monitoring — effects that might be felt across both markets.

This study explores some of the alternative explanations that potentially have common influence on both markets. Section 2 presents a review of current literature on drug shortages, along with a heuristic framework for understanding and predicting the potential effects of alternative influences on supply, demand, and ultimately shortage conditions. Section 3 explores (using econometric models) whether changes in quality monitoring by the FDA (e.g. more frequent inspections and citations of manufacturers) can be connected with shortages. Although this is an explanation that could potentially apply across both markets, and has been advanced by recent studies and position papers (e.g., GAO [11]; Committee Staff Report [13]), it has not been given rigorous empirical treatment in the past. Section 4 closes with a discussion of the empirical results of this paper in a broader context.

Ultimately, although there may be no single "cause" of drug shortages, one thing is certain: the overwhelming majority of shortages affect generic drugs. The key 
TABLE 1. Selected non-injectable drugs in shortage (UUDIS June, 2013)

\begin{tabular}{lrr}
\hline \hline drug name & Duration (mos.) & Notified date \\
\hline CARBAMAZEPINE XR TABS & 0 & $04 \mathrm{jun} 2013$ \\
GABAPENTIN ENCARBIL & 2 & $16 \mathrm{apr} 2013$ \\
CORTISONE TABLETS & 3 & $29 \mathrm{mar} 2013$ \\
ACYCLOVIR SUSPENSION & 5 & $29 \mathrm{jan} 2013$ \\
ATORVASTATIN & 7 & $26 \mathrm{nov} 2012$ \\
DOXYCYCLINE ORAL & 7 & $26 \mathrm{nov} 2012$ \\
PANTOPRAZOLE TABLETS & 7 & 29 nov2012 \\
RESERPINE & 9 & $26 \mathrm{sep} 2012$ \\
DOXAZOSIN TABLETS & 9 & $12 \mathrm{sep} 2012$ \\
BUSPIRONE & 9 & $21 \mathrm{sep} 2012$ \\
ESTRADIOL TABLETS & 9 & $18 \mathrm{sep} 2012$ \\
METHOTREXATE TABLETS & 10 & $20 \mathrm{aug} 2012$ \\
BUPRENORPHINE SL TABS & 18 & $29 \mathrm{dec} 2011$ \\
NALTREXONE TABLETS & 18 & $15 \mathrm{dec} 2011$ \\
TETRACYCLINE CAPSULES & 27 & $04 \mathrm{apr} 2011$ \\
ACYCLOVIR TABLETS & 44 & $23 \mathrm{oct} 2009$ \\
CIPROFLOXACIN 500 MG TABLETS & 45 & $14 \mathrm{oct} 2009$ \\
\hline \hline
\end{tabular}

difference between brand and generic drugs is the low margin available on generic drugs - particularly for those drugs that have been on the market for some time. With such low margins available, it is perhaps inevitable that shortages would result in a market where manufacturers may face weaker incentives to make investments in order to avoid supply disruptions. The United States may simply be a victim of its own success at creating an extremely competitive and price-sensitive market for generic drugs. The policy question, therefore, is whether (and how) the market could be shifted to an equilibrium that endogenously provides a desired level of quality and supply reliability without disruption. 


\section{BACKGROUND}

This section presents a sketch of some theoretical considerations underpinning the empirical work undertaken in this study.

2.1. Market incentives for generic manufacturers. It is important to recognize the role that the institutional structure of the U.S. generic market plays in creating conditions that are ripe for shortages. In particular, the notion of nearperfect substitutability of AB-rated generic drugs is built into the entire system. Many pharmacies and patients are compelled by payers to substitute the use of a generic product in lieu of the branded drug if one is available. And, by extension, generics are almost universally treated as perfect substitutes by the market. Pharmacy purchasing agents are free to select among competing manufacturers' products in order to meet their pharmacists' needs to fill prescriptions for a particular drug, so long as they are all approved AB-rated alternatives. Patients at a pharmacy generally only become aware of the manufacturer of their generic pills once they receive the bottle at the counter. They may receive the same manufacturer's product at the next refill, or they might not, depending on where the pharmacy (or its wholesaler) is sourcing its product at that time. There is very little either the patient, the doctor, or the pharmacist behind the counter can do to exert supplier preferences among generic drugs under the current market structure. ${ }^{5}$

This institutionalization of near perfect substitutability is, in fact, quite a rare phenomenon in markets. Even so-called commodities like wheat, corn, or oil have grading systems. This is not the case for generic pharmaceuticals.

Both quality/purity of product and reliability of supply are costly attributes for the manufacturer to provide, and they are generally invisible to buyers. Without FDA inspections and the occasional supply disruption, these characteristics are generally obscure to the market. Nevertheless, it is reasonable to assume that these are characteristics that enter into demand, and would affect prices if they were routinely observable and could be traded upon. In many markets where these attributes are observable, a premium is paid for them. However, as Woodcock

\footnotetext{
${ }^{5}$ Of course there are exceptions to this stylized story, for example in the case of narrow therapeutic index drugs where slight differences in bio-activity levels in different products are known to adversely affect patients switching among products.
} 
and Wosinska [14] point out, these attributes are not readily observable for generic pharmaceuticals, so it is difficult to pay a premium for them. ${ }^{6}$

One of the key consequences of this institutionalized substitutability is the "near Bertrand" price competition among manufacturers participating in these markets. ${ }^{7}$ In a market where suppliers are often asked to meet or beat the price of the competition to win a supply contract, price is set almost auction-style. Wholesalers can switch suppliers and reduce prices with a few phone calls.

These markets have delivered billions of units of thousands of products at prices often in the low single-digit pennies per pill range, so much of this story is one of great success for consumers.

Surviving this sort of price competition with both contracts and any sort of profit is almost certainly a matter of relentless cost-cutting. To give a rough idea of the relatively small scale of revenue earned on many generics, consider that the median average manufacturer price (AMP) for buspirone in the 2011-2013 time period was about $\$ 0.03$ per tablet. In 2012 Medicaid (generally the largest single payer for retail drugs in the United States) reimbursed about 85 million buspirone tablets for all of its fee for service patients nationwide. At the median AMP per-tablet this amounts to a little over $\$ 2.5$ million in total revenue spread across all participants in this relatively important slice of the market. Of the three manufacturers with more than 100,000 Medicaid units sold, only one would earn more than $\$ 1$ million in total revenue (not profit) on its 37 million units of Medicaid volume sold. ${ }^{8}$ Grossing this revenue up to the overall market (assuming Medicaid is roughly 15\% of the total), would yield about $\$ 6.6$ million in total U.S. buspirone revenue for this producer. These figures are a couple orders of magnitude smaller than might be experienced by a branded drug manufacturer. Although this example is essentially synthetic, it illustrates that the revenue, and therefore total profit, generated by these products

\footnotetext{
${ }^{6}$ It is notable that it was not unusual at one time for generic manufacturers to agree to supply reliability terms in their supply contracts, so it is not impossible to find methods to contract for these attributes.

${ }^{7}$ Conti \& Berndt, 2013

${ }^{8}$ Sources: CMS Medicaid State Drug Utilization Data, CMS published weighted average AMP data.
} 
can be quite limited. Staying profitable on the margin at these levels clearly presents a challenge.

Another thing that has to be recognized is that the typical modern generic manufacturer has literally hundreds of products on the market at any one time. Unlike brand manufacturers that may have a few key products on the market that are responsible for a significant fraction of their total revenue and profit, a generic manufacturer's revenues are frequently spread across a diffuse array of products. Their greatest profits are generally earned early in the evolution of the market postpatent expiration. Once price competition has had its relentless effect on prices for more mature generic products, revenues and profits for individual products may not make a large contribution to the bottom line of the company. They may continue selling these products if marginal costs are low, or if there are economies of scope associated with producing or selling a broad array of products.

It should therefore be little surprise, however, that when generic manufacturers are faced with supply disruptions of any magnitude on older low-margin products, they might not find it worthwhile to address them quickly, or at all. ${ }^{9}$ For example, it is not hard to imagine a production situation where some manufacturers' cost-cutting efforts could lead to a reduction in maintenance or product quality investments. Even if this ultimately results in a stoppage due to production-line failures, or regulatory interventions, this behavior may be optimal from the manufacturer's standpoint. This is a classic "race to the bottom" in both price and quality. If the current costs of plant maintenance and product quality investment exceeds the discounted expected value of lost profits due to a shutdown, then they are not worth undertaking. An option-value approach such as presented by Yurukoglu [15] would offer a refinement to this logic, but perhaps not a fundamentally different result. Once faced with the realization of a negative supply shock (such as product withdrawal or production line failure), the manufacturer may easily find

\footnotetext{
${ }^{9}$ The investment under uncertainty approach explored by Yurukoglu (2012 [15]) is potentially quite relevant in this context.
} 
higher returns to investment in, e.g., bringing a new Abbreviated New Drug Application (ANDA) product to market than attempting to resuscitate an older product for which prices may be limited. ${ }^{10}$

In short, there are several reasons to expect that generic supply could be inherently riskier than branded drug supply - particularly for low-priced "mature" products. As the first waves of blockbuster generics fade into the distant past, and the ranks of mature products on the production lists of manufacturers swell, it is not far-fetched to believe that the trend in observed shortages could be partly a result of this trend. These are also trends that would generally affect both markets for injectable and non-injectable drugs.

2.2. Regulatory activity - quality/purity concerns. Regulatory involvement may also have a role to play in drug shortages. Of particular interest are changes in policy, and time-inconsistent policies. In a market where product quality is not generally observable, but the actions of the regulator are, these actions may play an important role in setting expectations of both buyers and sellers in the market.

Suppose that the regulator, in this case the FDA, advertises that only a certain level of quality is permissible, and products below that threshold will not be allowed onto the market. If monitoring is perfect, then the presence of the product on the market is a clear signal that its quality is above the advertised regulatory threshold. Differentiation of quality above that threshold may not be worthwhile because additional investments in quality by the seller would be lost on buyers that only observe market presence as opposed to quality. The profit-maximizing decision of producers in this situation may be to undertake only those expenses required to pass the regulator's threshold and no more - leading to a generally consistent level of quality. This highlights the important role of the regulator in setting quality levels in markets where quality is otherwise unobservable. Were product quality an observable attribute, manufacturers might find it optimal to differentiate by optimizing around different levels of observable quality. ${ }^{11}$

\footnotetext{
${ }^{10}$ Prescription generic drug manufacturers must receive FDA approval via an ANDA before marketing each product.

${ }^{11}$ In this way, manufacturers might face a downward sloping demand for their product similar to the situation explored in Dorfman \& Steiner [3].
} 
In reality, the FDA does not have perfect oversight. Instead, it might inspect facilities at a known rate of probability. The manufacturer facing this uncertainty may well pick a level of quality that is below the advertised threshold if the probability of future inspection is less than one. In the limit, if the probability of inspection is zero, then investments in quality might only rise to a level such that manufacturing does not generate observable defects (like malformed pills, broken packaging, etc.) that could lead to consumer-led actions against the company. Whatever the probability of inspection, so long as it is the same for all manufacturers, and all manufacturers believe it to be the same, then all will target roughly the same level of quality and buyers will experience a consistent level of quality possibly somewhat below the advertised threshold. This intuition serves to explain the tendency of regulators such as the FDA and local health authorities to set relatively stringent goals.

As a hypothetical matter, manufacturers may assign different probabilities to the possibility of detection, and/or may be risk averse to varying degrees, which could lead them to pick heterogeneous levels of quality. For example, risk averse companies that believe in a high probability of inspection may feel compelled to make greater investments in quality, while those companies with less aversion to risk, or having a low assessment of the risk of inspection might be tempted to spend less on quality. To the extent that such heterogeneity in cost structures exists particularly if it translates to differences in marginal cost - an adverse selection problem could arise. If competition is Bertrand-like, then the producers most likely to survive in the market are those that are most willing to take a risk with low spending on quality giving them a low marginal cost and an advantage in price competition.

Even if the relatively risk-loving low-cost firms were eventually inspected and shut down, the consequences could be substantial in this scenario if they have already edged out higher quality competition, and there is no alternative higherquality supply available.

Setting clear expectations and time-consistent quality monitoring policies are key ingredients in this framework. If the regulator sets expectations both about the probability of inspection and the quality threshold in one period, but then 
changes one or the other of these subsequently, it could potentially cause either disruption or time-inconsistency issues. Suppose, for example, that the regulator raises the probability of inspection in a period subsequent to the period when manufacturers set their quality investment decisions. Caught off-guard with inadequate quality more frequently than expected, manufacturing would be subject to excess disruptions - i.e. shortages might occur. Now suppose the regulator in this circumstance alters its threshold downward to prevent excess disruptions. In this case the regulator has set up a time-inconsistency problem. Manufacturers, now knowing that the regulator's threat regarding attaining the threshold quality level is not credible, will likely take that into account in their future investments.

In short, absent observable quality, the FDA has an important role to play in setting equilibrium quality. To the extent that it may seek to raise equilibrium quality by raising either standards or (possibly more likely) the probability of inspection and detection of quality lapses, then a certain level of disruption is to be expected if some manufacturers are optimized around a different expectation of quality. To the extent that the Bertrand-like competition model is right, and some manufacturers moreover feel they face weak incentives to address supply issues with older low-cost drugs, then these disruptions could well be persistent. On the other hand, manufacturers may choose to address the issues that arise and re-enter the market. To the extent this raises costs, it would only be supportable under an expectation of higher future prices to support that cost structure.

Altered inspection rates, to the extent that they reflect exogenous regime changes, are thus a plausible factor that could contribute to increased shortage rates (at least in the short run), and this would be an effect likely to cut across both injectable and tablet drug markets. ${ }^{12}$

One example of a clearly articulated regime-change is the recent implementation of the Generic Drug User Fee Act (GDUFA). This act, which set a new structure

\footnotetext{
${ }^{12}$ Alternatively, one can imagine that unchanging inspection rates and rules could result in an endogenous indicator of the evolving quality decisions of manufacturers if these patterns take time to play out. For example, as price competition lowers spending on quality unobservables, more firms would trip the wire when they are inspected. This might predict changes in the rate of enforcement action given an inspection, but it is less clear whether this would predict a trend in inspections.
} 
of fees for the review of generic drug ANDAs, was intended in part to provide additional resources to the FDA for inspections. In fact, according to the FDA's Generic Drug User Fee Act Program Performance Goals and Procedures, "FDA will conduct risk-adjusted biennial CGMP surveillance inspections of generic API and generic finished dosage form (FDF) manufacturers, with the goal of achieving parity of inspection frequency between foreign and domestic firms in FY 2017."13 There two important aspects of this program goal: (1) the apparent recognition by FDA that inspection rates have not been at parity, and (2) the pre-announcement of the new inspection goals. The former suggests a real change in inspection regime for foreign manufacturers, while the latter should inform industry expectations and possibly smooth the transition.

2.3. Prices and shortages. Traditional economic explanations for shortages generally rest on price inflexibility as a key element of the story. In a standard neoclassical setting, "shortage" is a very short-run disequilibrium phenomenon caused by supply or demand shocks that are quickly corrected by upward price movements that serve to re-equilibrate supply and demand. Real shortages, where demand exceeds supply at going prices for extended periods of time, are generally considered to be a product of market failure: typically related to upward price inflexibility "sticky" prices.

ASPE's 2011 Issue Brief [8] points to some of the basic supply and demand conditions that apply pharmaceutical markets. In particular, both demand and supply are price inelastic (particularly in the short-run). For suppliers, these inelasticities generally stem from institutionally-driven requirements for approval of new manufacturing facilities and production lines as well as technological obstacles to adding capacity. For patients, the combination of medical necessity for these products and the fact that neither they, nor their doctors generally pay market prices for these products would generally argue for low responsiveness of demand to changes in price. ${ }^{14}$

\footnotetext{
${ }^{13}$ See: http://www.fda.gov/downloads/ForIndustry/UserFees/GenericDrugUserFees/UCM282505.pdf

${ }^{14}$ Third-party payers generally attempt to induce some price responsiveness in patients through utilization management tools like tiered copayments or prior authorization. Although these are effective at steering patients from more expensive brands to cheaper therapeutic alternatives, they are also a blunt tool. For example, a patient's copayment for a generic drug is generally lower
} 
Taken together, these conditions would potentially be a recipe for very large price increases in response to adverse supply shocks. ${ }^{15}$

But, there may be some contravening institutional factors. One might, for example, look at contracts as a standard explanation for why prices might move slowly upward in the presence of a supply shock. One of the most important types of contracts on this market are those governing how pharmacies are paid (reimbursement) for drugs by third party payers. A theory that has been expressed in popular press ties changes in Medicare reimbursement policies to increased shortage rates. Under that theory, Medicare's 2005 transition from Average Wholesale Price (AWP)-based reimbursement to Average Sales Price (ASP)-based reimbursement lowered both average margins and the upward responsiveness of Medicare reimbursements in the presence of adverse supply shocks. Yurukoglu (2012 [15]) examines this idea using a Nash equilibrium model of investment under uncertainty to capture capacity investment dynamics. This model predicts more frequent shortages in the presence of the ASP-based reimbursement that Medicare adopted in 2005. Yurukoglu's empirical results also suggest a lower frequency of shortages in the presence of higher (i.e. AWP-based) Medicare reimbursement.

This particular explanation does not appear on the surface to offer an explanation for the increased frequency of shortages in the market for non-parenteral drugs (which are not reimbursed under Medicare Part-B). However, there could be a private market analogue to the Medicare Part-B based reimbursement explanation for non-parenteral drugs. Much of the reimbursement for these types of drugs are governed by administrative rules that might not reflect market conditions. Particularly as they apply to generic drugs, these rules are not generally known publicly. For example, many generics are reimbursed on the basis of a maximum allowable cost (MAC) that is determined in a manner that is not generally transparent. To the extent that these payment methods are not flexible in the presence of supply

than for a similar brand, but is generally the same regardless of the underlying cost of the generic drug

${ }^{15}$ Here it needs to be reinforced that we are speaking in terms of market demand and market supply. Assuming a relatively competitive market, the demand curve facing the individual manufacturer is likely to be very price elastic, with a correspondingly elastic supply faced by individual buyers (for whom alternative supply is often just a phone call away). 
shocks, these contracts could introduce inflexibility in prices at a point in the supply chain that would place limits on the extent of price change that pharmacies can tolerate before losing money on sales - thus possibly disconnecting price and quantity in the market. This would also presume, however, that the institutions setting reimbursement rules have weak incentives to allow flexibility in them. This might not be true if there is competitive pressure to retain plan contracts. The complaints of beneficiaries unable to obtain their prescriptions due to a payor's inflexible reimbursement rules could be a source of such pressure.

There is a certain consumer appeal to upward price inflexibility for pharmaceuticals. Especially if demand elasticity is low, shortages could cause very substantial increases in price. Anecdotal evidence suggests that some drugs in shortage have been subject to "price gouging", which is a popular pejorative that often raises public concern. ${ }^{16}$ But, it is precisely elevated prices that are usually the equilibrating mechanism that simultaneously reduces demand (for example causing people to identify substitutes), and creates an incentive for new supply to get on the market quickly. Absent price responsiveness in the market, endogenous incentives for manufacturers to address supply issues are likely to be attenuated.

Although it is beyond the scope of this paper, merging aspects of the Yurukoglu investment model with the regulatory framework outlined above could yield more refined insights. In particular, the regulatory framework provides a richer model for the supply shock distribution built into the Yurukoglu model.

\section{EMPIRICAL EFFECTS OF REGULATORY ACTIVITY}

This section investigates the empirical linkages between FDA inspection and detection rates on shortage rates. As discussed above, change in regulatory activity is one of the variables expected to have an impact on shortage rates, at least in the short run as manufacturers adjust to a new equilibrium. Although increased FDA vigilance is sometimes directly blamed for the increases in drug shortages, there has not been rigorous analysis behind these statements. Moreover, to the extent that these connections are being made, they have been primarily focused on injectable drug shortages. The statistical models presented in this section suggest

\footnotetext{
${ }^{16}$ To the extent that some of these reports reflect concerns about grey market imports that potentially circumvent FDA rules, or are outright counterfeits, this concern could be well-justified.
} 
a connection between FDA inspection and citation rates and drug shortages that cuts across both parenteral and non-parenteral drugs.

3.1. Shortage data. The shortage data used in this study were provided by the University of Utah Drug Information Service (UUDIS), which also provides the information reported on the American Society of Health-System Pharmacists (ASHP) website. $^{17}$ The UUDIS shortage data have become a standard resource for researchers investigating shortages due both to its comprehensiveness and to its extensive time coverage. The Government Accountability Office (GAO) has issued two reports on shortages (GAO 2011 [11], and GAO 2014 [12]), both of which rely primarily upon the data gathered by UUDIS. ${ }^{18}$ As discussed in more detail below, the events tracked by UUDIS range in severity from temporary supply disruptions to full-blown shortages.

The FDA also provides online access to information on current and past drug shortages. ${ }^{19}$ There are two main distinguishing features between the FDA data on shortages and the UUDIS database. The first is that the FDA only publishes information on a shortage when the affected drug is considered medically necessary, i.e., if it is "used to treat or prevent a serious disease or medical condition, and there is no other available source of that product or alternative drug that is judged by medical staff to be an adequate substitute." ${ }^{20}$ This definition potentially omits reports of shortages that are of economic significance, or relevance to consumers, but nevertheless fall below FDA's medical necessity threshold. The most significant limitation of the FDA data for analytical purposes, however, is the lack of historical information that is made publicly available — only a few years of data on resolved

\footnotetext{
${ }^{17}$ These data first became available in 2001: "In 2001, ASHP entered into an agreement with the University of Utah Drug Information Service (UUDIS) to use bulletins developed by UUDIS to address pharmacists questions about shortages. Also in 2001, ASHP published guidelines on managing drug product shortages and launched a Drug Product Shortages Management Resource Center on its Web site." (ASHP 2002 [9])

${ }^{18}$ The data for this study is very similar to the data used by the GAO in its 2014 report.

${ }^{19}$ See http://www.fda.gov/Drugs/DrugSafety/DrugShortages/default.htm for more information on this source. UUDIS and FDA also share information.

${ }^{20}$ See ASHP [5] for discussion.
} 
shortages are available on the FDA website. Based on these considerations, the FDA shortage information was not used in this study. ${ }^{21}$

The supply disruptions tracked by UUDIS are voluntarily reported via several channels (e.g., the ASHP website shortage reporting feature.) ${ }^{22}$ Upon receiving a report, availability is researched among all manufacturers, along with reasons for the disruption and information about the potential for its resolution; it is then tracked. The ASHP website publishes data on shortages tracked by UUDIS, but only for drugs that meet its definition of shortage: "a supply issue that affects how the pharmacy prepares or dispenses a drug product or influences patient care when prescribers must use an alternative agent." ${ }^{23}$ Not all supply disruptions that are reported to UUDIS meet these formal shortage criteria, but are nevertheless tracked internally by UUDIS. According to UUDIS, if the disruption becomes significant enough to meet the ASHP shortage criterion, it will be listed on ASHP's public website where extensive information on availability from all current manufacturers is provided along with other information, such as reasons for shortage. ${ }^{24}$ As a result of this process, the data that UUDIS makes available to researchers tracks more supply disruptions than are reported on the ASHP website. ${ }^{25}$ Among the reasons given for this dichotomy is the desire to avoid worsening disruptions by prematurely disseminating information from early reports. ${ }^{26}$ One clear advantage of the UUDIS data beyond their time coverage, therefore, is that they also appear to be a more

\footnotetext{
${ }^{21}$ In its 2011 report [11], the GAO cited similar reasons for using the UUDIS data instead of FDA data in its retrospective analysis.

${ }^{22}$ See the ASHP website "Frequently Asked Questions" [10] for more information on what the reported data consist of, and how it compares to, e.g., the FDA shortage reports. See also Fox's 2011 presentation ([6]) for more background on the UUDIS reporting process and summary statistics generated from their data.

${ }^{23}$ ASHP 2009 [5], p. 1400.

${ }^{24}$ Telephone interview, May 2104.

${ }^{25}$ Information on the shortages tracked by the ASHP website are currently only available back to mid-2010 (earliest date observed on resolved shortage list as of 5/2014.) As a result, it is not possible to comprehensively identify which of the UUDIS-tracked disruptions were, in fact, reported on the ASHP website. Anecdotally, the number of disruptions identified in the UUDIS data may exceed those listed on the ASHP website by $50 \%$.

${ }^{26}$ ASHP 2009 [5] notes, for example, the potential for disruptions being exacerbated by purchasers hoarding product based on rumors of shortage.
} 
sensitive measure of supply disruption than the online ASHP shortage reports. ${ }^{27}$ In subsequent discussion, the events recorded in the UUDIS data will be referred to as shortages with the understanding that many of these events could be best described as disruptions rather than full-blown shortages.

The database received from UUDIS for this study contains information on 1,686 separate shortage events reported in the United States between January 2001 and June 2013. Each record contains information for one shortage event, including: drug name, date of first reported shortage, whether the shortage remains active, the ending date of the shortage if it is no longer active, reason for shortage, type of drug (parenteral vs. non-parenteral), American Hospital Formulary Service (AHFS) drug classification, and DEA schedule if the drug is a controlled substance. Certain drugs may appear multiple times in the data if they have experienced more than one shortage event over time. UUDIS also tracks a number of products that are beyond the scope of this study and consequently omitted from analysis, including: devices, vaccines, and vitamin therapies. ${ }^{28} \mathrm{~A}$ small number of additional products were eliminated from the data due to being listed as resolved, but having no end date. Omitting these products removes 137 events from the data, leaving 1,549 for further analysis.

Each year, an average of about $45 \%$ of the new events reported in the UUDIS data relate to non-parenteral drugs. The median length of resolved shortages is relatively similar for parenteral and non-parenteral drugs (5 months versus 4 months, respectively), but differences in average length are somewhat more pronounced (9.8 months versus 6.6 months, respectively. Focusing on events starting after 2003 reduces the average length of parenteral and non-parenteral shortages to 7.7 months

\footnotetext{
${ }^{27}$ It must be noted, however, that even when ASHP reports a shortage on its website, individual buyers may anecdotally be unaffected by the identified disruption. See Bhat, et al [1] for an example of this phenomenon.

${ }^{28}$ The following AHFS categories were eliminated from the UUDIS data: (16.) Blood Derivatives, (20.) Blood Formation, Coagulation, and Thrombosis Agents \& drug_name contains "FACTOR" (blood factor products), (80.) Serums, Toxoids, and Vaccines, (88.) Vitamins, (94.) Devices, (96.) Pharmaceutical aids.
} 
and 6.0 months, respectively. ${ }^{29}$ Taken together, the higher average length of parenteral shortages, and their higher frequency both contribute to the larger number of ongoing parenteral drug shortages noted in Chart 1.

For the statistical analysis, the UUDIS data were summarized into 150 monthly counts (2001-2013) of ongoing shortages (ongoing), and new shortage reports (starts) for parenteral and non-parenteral drugs. Though the number of ongoing shortages is clearly a variable of policy interest, it is also a stock variable, which likely induces autocorrelation in this series. There are sound reasons to expect that FDA regulatory activity would affect this stock both by potentially affecting the rate at which new shortages are started and by potentially altering the length of time that it takes to clear up supply issues resulting from FDA inspection. It turns out, however, that the stock of ongoing shortages does indeed turn out to be highly autocorrelated, with first-order autocorrelation coefficients in excess of 0.97. Dickey-Fuller (DF) statistics computed for these series (ongoing parenteral and non-parenteral shortages) are small and the corresponding DF-tests cannot reject the null hypothesis that unit roots are present in the data (p-values of 0.993 and 0.807 , respectively). This suggests either that these data should be differenced before performing regression analysis, or that the rate data (new shortage starts) be used instead. The shortage start data are indeed less autocorrelated with first-order autocorrelations of 0.57 and 0.49 for the parenteral and non-parenteral series, respectively. The Dickey-Fuller test soundly rejects the hypothesis of unit roots in these series (pvalue $<0.0000$ ). For modeling purposes, the count of new shortage starts will be treated as the dependent variable.

3.2. FDA inspection/citation data. The information on FDA regulatory activity used in this study come from two separate publicly down-loadable databases made available by the FDA on its website: one that focuses on the inspections performed by each of its centers and another that provides details on the citations (alleged CFR violations) that are noted during inspections. Each dataset has nonoverlapping information, thus both alternatives are used separately in the regression

\footnotetext{
${ }^{29}$ The coefficient of variation on the length of shortages is quite high-on the order of 1.3.
} 
analysis. The main limitation in these data is that they only include those events that have progressed to a point where the FDA is at liberty to disclose details. ${ }^{30}$

The monthly CDER drug inspection data are derived from a large database documenting all FDA inspections from October 1, 2008 to March 31, 2013. ${ }^{31}$ These data cover inspections made by all centers within the FDA, e.g., CBER, CDER, and $\mathrm{CDRH}$. Each inspection record lists the name of the firm inspected, its location, the date the inspection ended, the FDA center performing the inspection, the project area (focus of inspection), and the "district decision". The district decision records in summary form the outcome of the inspection. It is broken into three possible outcomes: NAI (No Action Indicated), VAI (Voluntary Action Indicated), and OAI (Official Action Indicated). ${ }^{32}$

The inspections database in this study contains information on 102,160 FDA inspections across all parts of the organization. The Center for Drug Evaluation and Research (CDER) accounts for 11,410 of these inspections, and the Center for Biologics Evaluation and Research (CBER) accounts for another 9,353 inspections. The majority of inspections (about 55\%) are associated with the activities of Center for Food Safety and Applied Nutrition (CFSAN), which monitors the food supply. Since the focus of this study is primarily on pharmaceuticals, the inspections of interest are those performed by CDER. The project area variable further breaks inspections down into categories. The majority of CDER's inspections $(8,348,73 \%$

\footnotetext{
${ }^{30}$ Particularly in months close to the end of the reporting period, the counts of included inspections and citations drops off significantly.

${ }^{31}$ These data are updated quarterly and can be downloaded at http://www.fda.gov/iceci/enforcementactions/ucm222557.htm. The version used in this study was downloaded in October 2013.

${ }^{32}$ The FDA website gives further detail on the meaning of these terms: "An OAI inspection classification occurs when significant objectionable conditions or practices were found and regulatory action is warranted to address the establishment's lack of compliance with statute(s) or regulation(s). A VAI inspection classification occurs when objectionable conditions or practices were found that do not meet the threshold of regulatory significance. Inspections classified with VAI violations are typically more technical violations of the FDCA. An NAI inspection classification occurs when no objectionable conditions or practices were found during the inspection or the significance of the documented objectionable conditions found does not justify further actions." See: http://www.fda.gov/AboutFDA/Transparency /PublicDisclosure/DraftProposalbyTopicArea/ucm211861.htm, accessed May, 2014)
} 
of the 11,410 total) are listed in the "Drug Quality Assurance" (DQA) project area. The next most prevalent project area is "Bioresearch Monitoring", which accounts for about $21 \%$ of CDER's inspections. The type of inspection most relevant to this study are the subset listed in the DQA project area.

Within CDER's DQA inspections it is worth noting that over $50 \%$ result in some kind of regulatory action. Although only $4.8 \%$ (401) of these inspections result in an "Official Action Indicated" outcome, another 48\% $(4,011)$ result in "Voluntary Action Indicated" - suggesting some kind of corrective action is needed, according to the FDA. Most of CDER's DQA inspections occur in the United States (74\%), as one would expect. Of the remaining foreign inspections, the largest fraction occur in India (18\%), and China (11\%), with the remainder spread among OECD countries.

Ideally, one would want to connect inspections mentioned in the FDA data (via company ownership and location) to the shortage events mentioned in the UUDIS data. However, it is typically difficult or impossible to make these direct connections given just the name and address information found in the FDA data. ${ }^{33}$ Nevertheless, FDA inspection data do provide insight into the overall intensity of FDA's activities, their regional focus, and outcomes. For the empirical exercise in this study, these data were processed into 60 monthly counts of overall inspections by region (US/EXUS) and district decision (NAI/VAI/OAI).

In addition to the detailed inspection data, the FDA separately makes available a database of citations listed for each of its inspections. This data set covers a longer period than the inspection data (from October 2005 to September 2012). These data only list inspections for which a citation was generated, so it does not

\footnotetext{
${ }^{33}$ For example, many firms in the pharmaceutical industry own and operate a complex web manufacturing locations, most of which are multi-product facilities. Information about which products are produced at particular facilities is generally not made available to the public, so even knowing that a particular firm was inspected at a particular location may only allow inferential conclusions about the drugs affected. This problem is exacerbated by the fact that the UUDIS data only provide drug name information, so historical data on which manufacturers produced a particular drug at the point of time of the inspection would be needed even for an inferential analysis. Also, since many of the inspected facilities, e.g. active pharmaceutical ingredient (API) plants in India and China, produce inputs for other manufacturers, the ultimate downstream impacts stemming from an inspection at one of these plants cannot be derived from public data.
} 
replace the inspections database as a source of information about the total number of inspections performed. Citations are recorded in the data as a specific reference to the portion of the Code of Federal Regulations (CFR) implicated, along with a text description of the specific violation. For each inspection with a citation, multiple records with different CFR references may be recorded in this database. Overall, FDA's citation data contain 157,301 individual citation records across all of FDA's centers; 22,791 are related specifically to CDER inspection activities. Unlike the inspection data, the citation data are not further sub-dividable into project area, e.g., DQA activities versus Bioresearch Monitoring. However, it is possible to distinguish citations related to 21 CFR Part 211: "Current Good Manufacturing Practice for Finished Pharmaceuticals" (CGMP) from others. CGMP citations are a dominant fraction $(97.25 \%)$ of the total citations. The relatively small number of remaining citations are dominated $(93 \%)$ by Part 314 references: "Applications for FDA Approval to Market a New Drug". Keeping only citations related to Part 211 , leaves 22,164 total citations over the covered time period.

The 22,164 CDER CGMP citations identified in the FDA citation database are linked to 3,478 unique inspection events (month, manufacturer, country combinations), meaning that approximately 6.4 citations are given out per (citation generating) inspection. ${ }^{34}$ Review of the particular citations involved with each of the CGMP inspections in this database reveals 236 different CFR references. The five most frequently cited are: 21 CFR 211.192 (1401 times), 21 CFR 211.22(d) (969 times), 21 CFR 211.100(a) (909 times), 21 CFR 211.25(a) (905 times), and 21 CFR 211.110(a) (701 times). No attempt was made to classify the CFR references qualitatively. ${ }^{35}$ For each CFR reference a number of different text descriptions can show up. For example, for citations referencing 21 CFR 211.192 there are 36 different associated text descriptions, each alleging a specific form of quality assurance lapse. A large majority of the inspections and citations in this database occur at US locations ( $97 \%$ in each case).

\footnotetext{
${ }^{34}$ In a handful of instances (less than 20) an inspection occurred at more than one location for a particular manufacturer within a country and month. Many of these occur on the same or very proximate dates in geographically close locations, so are treated here as a single event.

${ }^{35}$ Although qualitative distinctions clearly exist, making such judgments would involve challenges.
} 
Both the number of citations and the number of unique inspections leading to a citation (firm/date combinations) were processed into 84 monthly summary counts by region (US/EXUS). Comparing the inspection and citation data for the years where the two datasets overlap reveals that in the US, the number of inspections with citations in the citation dataset tracks the number of inspections listed with a district decision of "VAI" or "OAI" in the inspection dataset reasonably well. There is less correspondence between these series for inspections occurring outside the US. ${ }^{36}$

The patterns of correlation among the various measures of FDA activity suggest caution when attempting to use these measures in conjunction with one other on the right hand side of a regression equation. For example, there is a relatively high degree of correlation between the count of inspections with citations and total inspections (0.86 and 0.82 correlation, US/Ex-US respectively). As expected, there is also a high degree of correlation between the number inspections with VAI/OAI district decisions and inspections with citations (0.91). Factor analysis of these data confirm that two factors can account for almost all of the variation in the 6 different FDA activity measures (excluding totals which are perfect linear combinations of other variables). Inspection of the factor loadings suggests a strong distinction between measures of US and Ex-US activity, whether it be overall inspections or inspections with citations.

For modeling purposes, only six measures of FDA activity were thus retained: US/Ex-US inspections (2008-2013) and US/Ex-US citations (2005-2012) along with their totals. As with the measure of new shortage starts, the FDA citation and inspection data exhibit modest autocorrelation (first-order autocorrelation generally below 0.5 ). Dickey-Fuller tests soundly reject a null hypothesis of unit roots in these data. Figure 4 illustrates the pattern over time for the FDA variables. Note that both of the US series (inspections and citations) have apparent seasonal patterns with a discernible dip near the end of each year.

These data were then combined with the parenteral and non-parenteral shortage data, then pooled (stacked) into a dataset with 300 total observations (fewer for

\footnotetext{
${ }^{36}$ In particular, there appear to be considerably fewer (often months with zero) inspections with citations compared to "VAI" / "OAI" events in the inspection data, although the correlation is still reasonably high $(0.81)$.
} 
FIGURE 4. FDA inspection and citation data

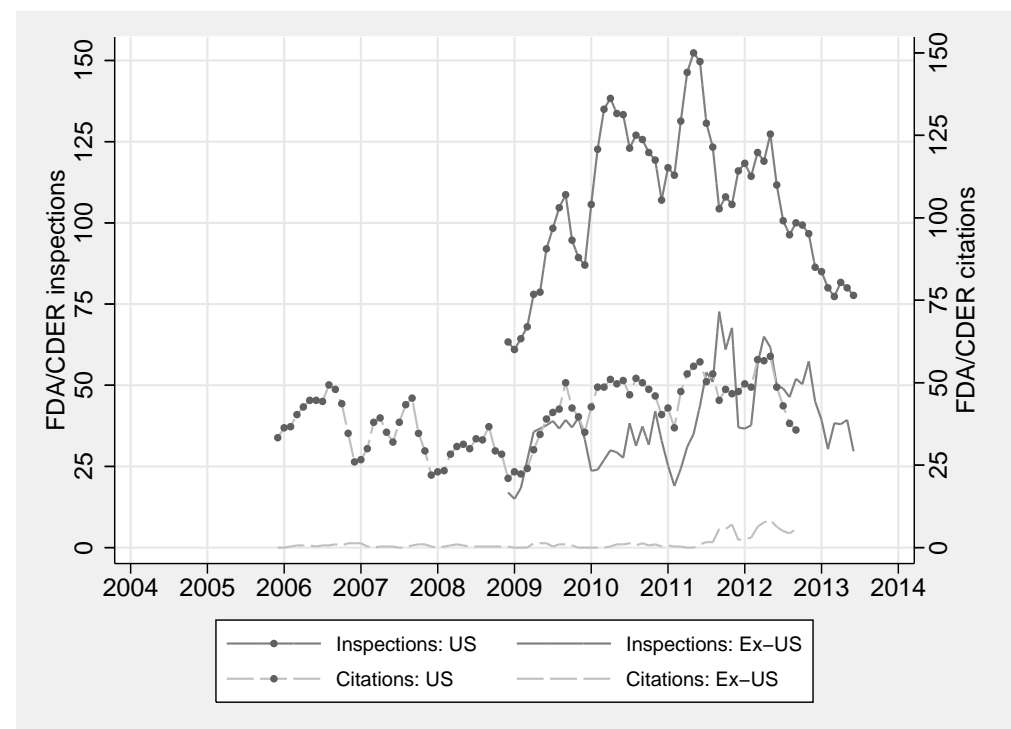

Source: FDA.

TABLE 2. Summary statistics for variables used in statistical analysis

\begin{tabular}{lrrrrrr}
\hline \hline Variable & Obs & Mean & Std. Dev. & Min & Median & Max \\
\hline pflag & 300.00 & 0.50 & 0.50 & 0.00 & 0.50 & 1.00 \\
starts & 300.00 & 5.16 & 3.79 & 0.00 & 5.00 & 22.00 \\
cites & 168.00 & 41.40 & 13.23 & 16.00 & 40.50 & 84.00 \\
cites_US & 168.00 & 40.01 & 12.29 & 15.00 & 39.50 & 73.00 \\
ites_EXUS & 168.00 & 1.39 & 2.57 & 0.00 & 0.00 & 15.00 \\
insp & 114.00 & 143.40 & 35.36 & 66.00 & 144.00 & 239.00 \\
insp_US & 114.00 & 105.05 & 27.50 & 55.00 & 108.00 & 160.00 \\
insp_EXUS & 114.00 & 38.35 & 19.41 & 7.00 & 34.00 & 126.00 \\
\hline \hline
\end{tabular}

the shorter FDA inspection data). Table 3.2 provides summary statistics for the variables used in the statistical analysis. 
FiguRE 5. Drug shortage rates, FDA inspections, FDA citations

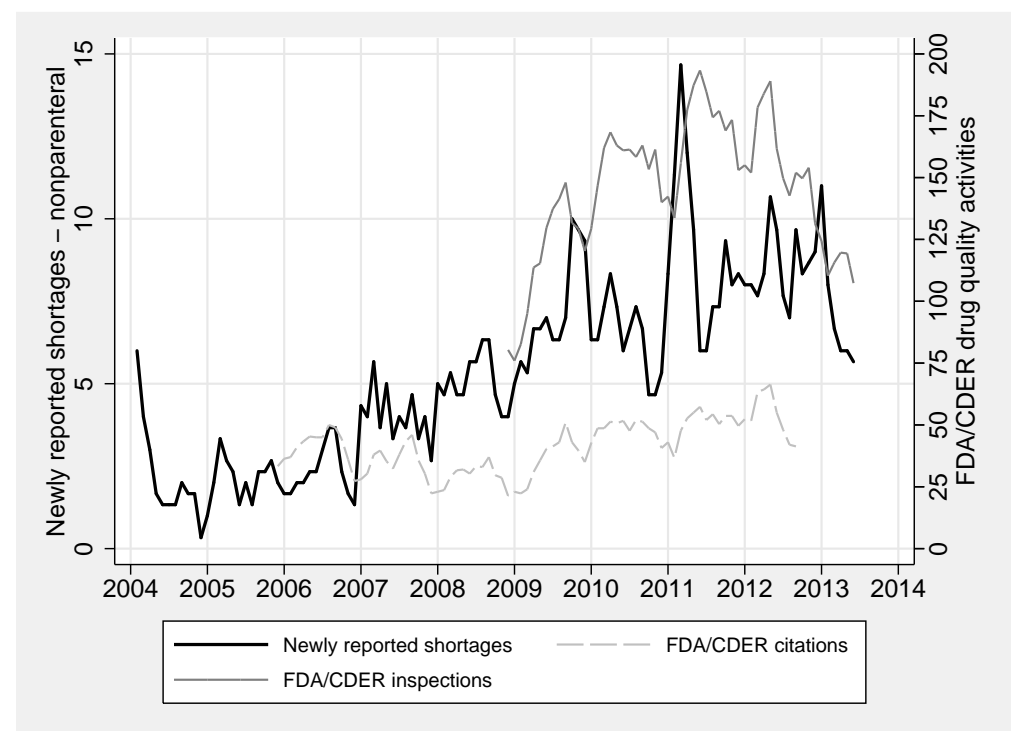

Sources: UUDIS, FDA.

3.3. Modeling and analysis. Figure 5 plots the total number (US/Ex-US) of monthly FDA inspections and citations against the number of newly reported shortages for non-injectable drugs. ${ }^{37}$

These charts suggest the potential for lagged effects and other dynamics in the relationship between FDA activity and drug shortages. Panel time-series regression models were estimated to investigate these relationships. These models are designed to be predictive in nature, and are used to determine if current and past FDA activity has an effect on new drug shortage reports. These models do not represent a reduced-form estimation of any particular underlying structural model, but can potentially be useful for identifying causation in the sense of Granger. ${ }^{38}$ The general

\footnotetext{
${ }^{37}$ The data in this figure have been smoothed with a one-quarter moving average to improve readability. These same charts appear similar for parenteral drug shortages, and have been omitted for the sake of brevity.

${ }^{38}$ Taking a more traditional approach using IV estimation presents the typical problem of identifying an appropriate instrument, in this case for FDA regulatory activity. Fully exogenous changes, such as turnover in FDA leadership driven by political changes or (possibly) implementation of the GDUFA could serve as exogenous sources of variation. The FDA inspection and citation data provide relatively little data spanning such regimes, however.
} 
form of these models is the following:

$$
y_{i t}=\alpha+\beta_{0} \cdot \mathbf{X}_{t}+\beta_{1} \cdot \mathbf{X}_{t-1}+\ldots+\beta_{l} \cdot \mathbf{X}_{t-l}+\gamma \cdot \mathbf{p f l a g}+\epsilon_{i t}
$$

Where $y_{i t}$ is the number of new shortages reported for drug type $i$ (injectable, non-injectable) in time $t$. The variable $\mathbf{X}_{t-l}$ is the measure of regulatory activity (citations or inspections) for time $t$ lagged by $l$ periods. The variable pflag is an indicator equal to one for injectable (parenteral) drugs and zero otherwise.

Focusing first on the citation data, which provides a longer time series for estimation, Table 3 reports the results of six models of drug shortage where the independent variables are counts of FDA citations and the dependent variable is the count of drug shortages reported by UUDIS described above. Three of the models are estimated using OLS and three are estimated using Negative Binomial Regression (NBR), a more flexible form of Poisson model that treats the dependent variable as a count. Model (1) contains contemporaneous total citations along with a three-month distributed lag of citations. No interaction effects between pflag and the citation variables were included in this baseline model. Only one of the parameters in this model is statistically significant at the $5 \%$ level (2nd lag). A Wald test for the joint significance of the FDA citation parameters has a p-value of 0.0010, which suggests an overall statistically significant relationship between these variables and drug shortage rates.

Model (2) adds lags of up to six months to the model. In this model, several of the individual coefficients on the FDA citation counts are statistically significant beyond the $5 \%$ level. The Wald test for their joint significance has a p-value less than 0.0001, which again suggests an overall statistically significant relationship between overall FDA inspections with citations and shortages. The Wald test for the joint significance of the added lag terms has a p-value of 0.0162 and there is a notable increase in the adjusted $R^{2}$ when these lags are added.

Noting the discrepancies between citations and inspections with actions indicated in the Ex-US data, Model (3) uses only citations at US-based facilities on the right hand side. The results of this regression are broadly similar to model (2).

Models (4)-(6) examine the same relationships using NBR estimation as an alternative to OLS. These results follow a very similar qualitative pattern compared 
to the OLS models, both in terms of the overall significance of the parameters associated with lagged citations as well as the pattern of significance of some of the individual coefficients.

First-order residual autocorrelation for both the OLS and NBR models is relatively low for the non-parenteral data (0.22 or less), but is somewhat higher (up to 0.55 ) for the parenteral data. An alternative model including interaction effects between pflag and the citation variables was run to check whether these differences in autocorrelation were driven by the estimation of a common lag structure for both parenteral and non-parenteral citations. For these interacted models (not reported in the table), the common effects remain jointly significant at the $5 \%$ level for the OLS model and less than $1 \%$ for the NBR model. The interaction effects are jointly insignificant in both cases - suggesting both a common lag pattern and that other factors may be contributing to the higher autocorrelation in the parenteral residuals.

Table 4 reports the results of six additional models of drug shortage based on the shorter inspection data series. As with the citation data, Model (1) is estimated via OLS and contains contemporaneous total inspections (insp) and a three-month distributed lag of total inspections. In this case, only one of the individual coefficients on total inspections is significant at the $5 \%$ level (2nd lag). A Wald test for the joint significance of the FDA inspection parameters has a p-value of 0.0115 , which suggests the presence of an overall statistically significant relationship between lagged inspection rates and drug shortage rates. Model (2) adds lags of up to six months to the model. In this model, none of the individual coefficients on the FDA inspection counts is statistically significant, and the Wald test for joint significance of the inspections is also insignificant. The Wald test for the added lags shows their parameters to be jointly insignificant. The results of model (3) (US inspection rates) are broadly similar. The NBR models (4)-(6) follow a similar qualitative pattern, but with stronger p-values attached to the tests of the joint significance for the lagged inspection variables.

Residual autocorrelations in these data are generally smaller than in the models with citations as regressors. As with the models of citations, additional models 
TABle 3. Regression results - FDA Citations

\begin{tabular}{|c|c|c|c|c|c|c|}
\hline & $\begin{array}{c}(1) \\
\text { OLS (Total) }\end{array}$ & $\begin{array}{c}(2) \\
\text { OLS (Total) }\end{array}$ & $\begin{array}{c}(3) \\
\text { OLS (US) }\end{array}$ & $\begin{array}{c}(4) \\
\text { NBR (Total) }\end{array}$ & $\begin{array}{c}(5) \\
\text { NBR (Total) }\end{array}$ & $\begin{array}{c}(6) \\
\text { NBR (US) }\end{array}$ \\
\hline \multicolumn{7}{|l|}{ main } \\
\hline \multirow[t]{2}{*}{ pflag } & 0.889 & 0.833 & 0.833 & 0.133 & 0.122 & 0.117 \\
\hline & $(0.148)$ & $(0.176)$ & $(0.175)$ & $(0.146)$ & $(0.167)$ & $(0.180)$ \\
\hline \multirow[t]{2}{*}{ cites } & 0.0440 & 0.0409 & 0.0474 & 0.00659 & 0.00630 & 0.00726 \\
\hline & $(0.147)$ & $(0.205)$ & $(0.152)$ & $(0.146)$ & $(0.169)$ & $(0.119)$ \\
\hline \multirow[t]{2}{*}{ 1_1_cites } & 0.00351 & -0.00335 & 0.00102 & 0.000992 & 0.000269 & 0.000980 \\
\hline & $(0.897)$ & $(0.910)$ & $(0.973)$ & $(0.798)$ & $(0.948)$ & $(0.822)$ \\
\hline \multirow[t]{2}{*}{ 1_2_cites } & 0.0751 & 0.0628 & 0.0617 & 0.0107 & 0.00866 & 0.00860 \\
\hline & $(0.007)$ & $(0.032)$ & $(0.052)$ & $(0.005)$ & $(0.023)$ & $(0.038)$ \\
\hline \multirow[t]{2}{*}{ 1_3_cites } & -0.0192 & -0.0548 & -0.0503 & -0.00285 & -0.00858 & -0.00801 \\
\hline & $(0.499)$ & $(0.065)$ & $(0.100)$ & $(0.534)$ & $(0.055)$ & $(0.079)$ \\
\hline \multirow[t]{2}{*}{ 1_4_cites } & & 0.00695 & 0.00264 & & 0.000761 & 0.000145 \\
\hline & & $(0.818)$ & $(0.931)$ & & $(0.851)$ & $(0.972)$ \\
\hline \multirow[t]{2}{*}{ 1_5_cites } & & 0.0261 & 0.0364 & & 0.00467 & 0.00627 \\
\hline & & $(0.344)$ & $(0.205)$ & & $(0.179)$ & $(0.082)$ \\
\hline \multirow[t]{2}{*}{ 1_6_cites } & & 0.0613 & 0.0642 & & 0.00921 & 0.00967 \\
\hline & & $(0.048)$ & $(0.042)$ & & $(0.023)$ & $(0.018)$ \\
\hline \multirow[t]{2}{*}{ _cons } & 1.775 & 0.459 & -0.294 & 1.145 & 0.927 & 0.808 \\
\hline & $(0.122)$ & $(0.681)$ & $(0.810)$ & $(0.000)$ & $(0.000)$ & $(0.000)$ \\
\hline \multirow[t]{2}{*}{ lnalpha } & & & & -1.738 & -1.913 & -1.931 \\
\hline & & & & $(0.000)$ & $(0.000)$ & $(0.000)$ \\
\hline$N$ & 162 & 156 & 156 & 162 & 156 & 156 \\
\hline$R^{2}$ & 0.110 & 0.158 & 0.162 & & & \\
\hline$R^{2} a d j$ & 0.082 & 0.112 & 0.116 & & & \\
\hline \multirow[t]{2}{*}{ Wald (cites) } & 4.89 & 5.19 & 5.18 & $20.45^{*}$ & $41.13^{*}$ & $41.26^{*}$ \\
\hline & $(0.0010)$ & $(0.0000)$ & $(0.0000)$ & $(0.0004)$ & $(0.0000)$ & $(0.0000)$ \\
\hline \multirow[t]{2}{*}{ Wald (added lags) } & & 3.54 & 4.15 & & $12.11^{*}$ & $14.16^{*}$ \\
\hline & & $(0.0162)$ & $(0.0074)$ & & $(0.0070)$ & $(0.0027)$ \\
\hline
\end{tabular}

using interaction effects to allow more flexibility were also fitted. In both cases (OLS and NBR), the added interactions were jointly insignificant.

\section{Discussion}

The key insight introduced at the beginning of this paper is that generic drug shortages are not a phenomenon isolated to parenteral drugs. Indeed, the overall similarity between the time pattern of shortages in parenteral and non-parenteral drugs is striking, and indicates that some of the causes are likely shared. Three possibilities are offered as potentially cross-cutting explanations: market structure, 
TABLE 4. Regression results - FDA Inspections

\begin{tabular}{|c|c|c|c|c|c|c|}
\hline & $\begin{array}{c}(1) \\
\text { OLS (Total) }\end{array}$ & $\begin{array}{c}(2) \\
\text { OLS (Total) }\end{array}$ & $\begin{array}{c}(3) \\
\text { OLS (US) }\end{array}$ & $\begin{array}{c}(4) \\
\text { NBR (Total) }\end{array}$ & $\begin{array}{c}(5) \\
\text { NBR (Total) }\end{array}$ & $\begin{array}{c}(6) \\
\text { NBR (US) }\end{array}$ \\
\hline \multicolumn{7}{|l|}{ main } \\
\hline \multirow[t]{2}{*}{ pflag } & 0.704 & 0.686 & 0.686 & 0.0798 & 0.0780 & 0.0653 \\
\hline & $(0.345)$ & $(0.387)$ & $(0.369)$ & $(0.371)$ & $(0.396)$ & $(0.458)$ \\
\hline \multirow[t]{2}{*}{ insp } & 0.0145 & 0.0103 & 0.0305 & 0.00183 & 0.00131 & 0.00349 \\
\hline & $(0.299)$ & $(0.504)$ & $(0.151)$ & $(0.274)$ & $(0.471)$ & $(0.155)$ \\
\hline \multirow[t]{2}{*}{ 1_1_insp } & 0.0107 & 0.00835 & 0.00701 & 0.00145 & 0.00106 & 0.000913 \\
\hline & $(0.408)$ & $(0.589)$ & $(0.739)$ & $(0.343)$ & $(0.540)$ & $(0.696)$ \\
\hline \multirow[t]{2}{*}{ 1_2_insp } & 0.0253 & 0.0268 & 0.0380 & 0.00302 & 0.00301 & 0.00441 \\
\hline & $(0.045)$ & $(0.124)$ & $(0.102)$ & $(0.028)$ & $(0.094)$ & $(0.082)$ \\
\hline \multirow[t]{2}{*}{ 1_3_insp } & -0.0124 & -0.0163 & -0.0148 & -0.00137 & -0.00194 & -0.00164 \\
\hline & $(0.374)$ & $(0.339)$ & $(0.496)$ & $(0.440)$ & $(0.361)$ & $(0.509)$ \\
\hline \multirow[t]{2}{*}{ 1_4_insp } & & 0.00447 & 0.0106 & & 0.000754 & 0.00149 \\
\hline & & $(0.785)$ & $(0.674)$ & & $(0.676)$ & $(0.595)$ \\
\hline \multirow[t]{2}{*}{ 1_5_insp } & & -0.00109 & -0.00349 & & 0.0000844 & -0.000138 \\
\hline & & $(0.942)$ & $(0.865)$ & & $(0.961)$ & $(0.951)$ \\
\hline \multirow[t]{2}{*}{ 1_6_insp } & & 0.0113 & 0.00716 & & 0.00131 & 0.000760 \\
\hline & & $(0.414)$ & $(0.714)$ & & $(0.402)$ & $(0.715)$ \\
\hline \multirow[t]{2}{*}{ _cons } & 2.112 & 1.290 & -0.388 & 1.313 & 1.219 & 1.034 \\
\hline & $(0.203)$ & $(0.565)$ & $(0.854)$ & $(0.000)$ & $(0.000)$ & $(0.000)$ \\
\hline \multicolumn{7}{|l|}{ lnalpha } \\
\hline \multirow[t]{2}{*}{ _cons } & & & & -2.521 & -2.482 & -2.689 \\
\hline & & & & $(0.000)$ & $(0.000)$ & $(0.000)$ \\
\hline$N$ & 108 & 102 & 102 & 108 & 102 & 102 \\
\hline$R^{2}$ & 0.097 & 0.089 & 0.155 & & & \\
\hline$R^{2} a d j$. & 0.0533 & 0.010 & 0.082 & & & \\
\hline \multirow[t]{2}{*}{ Wald (insp) } & 3.42 & 1.60 & 2.33 & $14.94^{*}$ & $11.82^{*}$ & $18.81^{*}$ \\
\hline & $(0.0115)$ & $(0.1446)$ & $(0.0312)$ & $(0.0048)$ & $(0.1066)$ & $(0.0088)$ \\
\hline \multirow[t]{2}{*}{ Wald (added lags) } & & 0.37 & 0.18 & & $1.39^{*}$ & $0.82^{*}$ \\
\hline & & $(0.7742)$ & $(0.9072)$ & & $(0.7085)$ & $(0.8459)$ \\
\hline
\end{tabular}

$p$-values in parentheses, ${ }^{*}$ denotes chi-square statistic.

regulatory activity, and pricing. One of these, regulatory activity, is explored empirically.

The regression models presented in this paper identified a consistent and statistically significant predictive relationship between FDA regulatory activity in the drug market (i.e. drug quality inspections and citations) and the incidence of new drug shortages. The models tested indicate that the pattern of this relationship is generally shared across both parenteral and non-parenteral drugs. This result 
suggests that changes in regulatory activity may be one of the cross-cutting factors contributing to the ongoing wave of drug shortages.

It is important not to over-interpret this result, however. The OLS models, for example, exhibit relatively modest $R^{2}$ statistics. This indicates that, although these models are predictive, a substantial amount of variation in new shortage starts remains unexplained by this single factor. This should not come as a surprise given the discussion on other likely factors contributing to drug shortages; regulatory activity is only one of those factors. And, because other factors that may be important are not accounted for in these models, caution is advisable when interpreting the results presented here (particularly with respect to individual coefficient estimates).

It is also important to recognize the economic and regulatory context of this result. Apparent changes in FDA oversight activity may signal attempts to reestablish quality thresholds that may have eroded or that have been applied unevenly as the industry has evolved. The program goals of the GDUFA are potentially an example of this. Supply interruptions resulting from this activity can be viewed as a necessary step on the road to a different equilibrium. As discussed, once oversight reaches a consistent and anticipated level within the industry, a new equilibrium level of quality can be established and shortages should resolve given adequate price responsiveness. In other words, if shortages are caused by changes in regulatory oversight relative to expectations, then they should be transitory in nature - smoothing out once all participating manufacturers adjust accordingly.

Pricing and market structure are important factors to consider in future empirical work. For example, public controversy has recently arisen over a pattern of spikes in retail (i.e. non-parenteral) generic drug prices. ${ }^{39}$ These reports may be connected with disruptions that may, or may not, lead to outright shortages, and appear to point toward an interesting avenue of research. Although a recent GAO study finds that the number of generic drug shortages was in decline by 2013 (GAO, 2014 [12]), it is clear from the number of ongoing shortages that fragility in the supply of generic drugs remains a concern in the United States.

${ }^{39}$ See, e.g., Adam Fein's November 2013 blog entry [4]. 


\section{REFERENCES}

1. Russel Roberts John W. Devlin Bhat, Subha, Posted versus actual drug shortages, Am J Health-Syst Pharm 69, 1363.

2. Rena M. Conti and Ernst R. Berndt, Anatomy of U.S. cancer drug shortages: Technology, market structure and price competition, Working Paper (2013).

3. Robert Dorfman and Peter O. Steiner, Optimal advertising and optimal quality, American Economic Review 44, 826.

4. Adam J. Fein, Retail generic drug costs go up up and away, www.drugchannels.net (2013).

5. Annette Birt Ken B. James Heather Kokko Sandra Salverson Fox, Erin R. and Donna L. Soflin, Ashp guidelines on managing drug product shortages in hospitals and health systems, Am J Health-Syst Pharm 66, 1399.

6. Erin R. Fox, Drug shortage update current status and significant trends, Online presentation: http://www.fda.gov/downloads/Drugs/NewsEvents/UCM274565.pdf (2011).

7. John R. Graham, The shortage of generic sterile injectable drugs: Diagnosis and solutions, Mackinac Center Policy Brief (2012).

8. K Haninger, A Jessup, and MA Koehler, Economic analysis of the causes of drug shortages, ASPE Issue Brief (Department of Health and Human Services, Office of the Assistant Secretary for Planning) (2011).

9. American Society of Health System Pharmacists, Provisional observations on drug product shortages: Effects, causes, and potential solutions, Am J Health-Syst Pharm 59, 2173.

10. _ _ http://www.ashp.org/menu/drugshortages/faqs.html, ASHP Website, accessed May 2014 (2014).

11. US Government Accountability Office, Drug shortages-FDAs ability to respond should be strengthened (GAO-12-116), United States Government Accountability Office (2011).

12. __ Drug shortages_public health threat continues, despite efforts to help ensure product availability (GAO-14-194), United States Government Accountability Office (2014).

13. Staff report, FDAs contribution to the drug shortage crisis, U.S. House of Representativesw 112th Congress Committee on Oversight and Government Reform (2012).

14. Janet Woodcock and Marta Wosinska, Economic and technological drivers of generic sterile injectable drug shortages, Clinical Pharmacology \& Therapeutics 93, no. 2, 170.

15. Ali Yurukoglu, Medicare reimbursements and shortages of sterile injectable pharmaceuticals, National Bureau of Economic Research Working Paper No. 17987 (2012). 